\title{
Branding Strategy of West Java: Fashion Products of The Creative Industry
}

\author{
Popy Rufaidah ${ }^{1 *}$ \\ ${ }^{1}$ Padjadjaran University, Bandung, Indonesia
}

\begin{abstract}
In past research, branding strategy application in the creative industry has been left largely unexplored. This study aims to investigate the types of branding strategy elements perceived as the distinctiveness of West Java in fashion products of the creative industry. This study is a cross-sectional study using survey method, which is designed to describe the frequency of customer perceptions of branding strategy elements such as products design, marketing communication-tools and physical environment. The data used in this study is primary and secondary data. The primary data is obtained from the results of observations, interviews and survey using questionnaires. The respondents of the study are the customers of fashion products in the creative industry who have been living in West Java at lest for two years. The study concludes that there are some critial points in building West Java brand through several branding strategy elements that need more attention such as (i) the performance of blogs and websites as marketing promotional tools used by companies in the creative industry is perceived low (37\%); (ii) most of the fashion products marketed by companies in the creative industry are perceived similar and not unique (57\%); (iii) the logo of the fashion products sold in the market by creative industry players is perceived not attractive (37\%) and; the places where the fashion products are sold are perceived not clean (46\%).
\end{abstract}

Keywords: Branding Strategy, Fashion Products, Creative Industry

\section{INTRODUCTION}

The development of creative industries in West Java, which consists of twenty-seven cities and districts, is very interesting to be studied. West Java Provincial Government has been an initiator of the creative industry in Indonesia by giving birth to an organization called the Committee of West Java Creative Economic Development in 2011. This organization has a role to develop the quantity and quality of creative economy. Research related to the creative industry is growing, such as in the fields of art and culture, verbal and visual communication, information technology and information systems, policy, management science, and other fields of science.

Referring to the Presidential Instruction of the Republic of Indonesia Number 6 of 2009, the creative industry consists of: Advertising (creation and production of advertisement); Architecture (Township, Gardening, etc.); Art and Antiques Market; Craft; Design (interior, exterior, graphics); Fashion; Movies,

* Corresponding author. Email address: popy.rufaidah@unpad.ac.id 
Video and Photography; Interactive Games; Music; Performing Arts; Publishing and Printing; Computer Services and Software; Radio and Television; and Research and Development. It is interesting to note that the products produced by the creative industry have not had a good identity performance as their brand distinctiveness. In particular, one of the creative industry clusters of interest to be studied is the fashion cluster (clothing).

Companies that can maintain a position in the competition are those known for their use of branding strategy (Porter 1988). As competition in the market is increasingly tight, more and more companies apply branding strategy as one way to improve the performance of product penetration to their target market, differentiate their product offerings, and strengthen the brand image of the product (Singh 2014). Companies must discover how to create successful brands in their target markets while assessing their brand effectiveness and branding strategies. Successful brands in the marketplace are able to create alliances for mutual benefit for the company (Aaker, 1996).

Strebinger (2014) found that branding strategies for products are determined by industry ( 23 percent of variance), the overall strategy of the company ( 28 percent), and the remaining variance being product-level decisions deviating from both. Service and consumer durables companies lean more towards corporate branding than consumer nondurables. Research in the field of branding strategy has been done extensively such as by Strebinger (2014) who referred his study to Murphy (1987), Olins (1989), Laforet and Saunders (1994), Kapferer (1997), Aaker and Joachimsthaler (2000), Urde (2003) and Keller (2003). Moreover, research that focuses on measuring consumer perceptions of fashion products produced by creative industries made from textiles is still very rare.

Results of study of Creative Economy Initiation Team (taskforce) of West Java Province 2011, along with the Local Government Planning Agency of West Java, wherein the author is involved as the Team Leader, show that the creative industries of West Java have a major weakness, that is the brands of the products have not been registered $(81 \%)$. It is interesting, nevertheless, how the consumer perceptions of the use of brands on fashion products made from textiles in West Java has never been studied before. So this research aims to investigate how the consumers of fashion products in the creative industry in West Java perceive the branding strategy applied by small medium enterprises (SMEs).

\section{LITERATURE REVIEW}

Brand is a company's long-term investment, which if managed with the maximum, will certainly provide benefits for the company. To be able to maintain a brand in the long term, it is important for a company to apply appropriate branding strategy to its products. One-way to build a brand strategy is by applying brand elements (brand identity), which are "those trademarkable devices that serve to identify and differentiate the brand" (Keller, 2008: 140). Brand element or brand identity is any means or mark that serves to differentiate and identify the brand. The literature review of branding strategy can be traced back to the literatures on brands, brand identity, visual identity, products and promotions. 
Extensive literature review on branding strategy can be traced on the study of Strebinger (2014) where he mentioned that branding strategy is often used synonymously with the terms "brand architecture" (Aaker and Joachimsthaler, 2000:8; Douglas et al., 2001; Kapferer, 2012:309) or "brand structure" (Laforet and Saunders, 1994/2007). Branding strategy is an activity undertaken by a company to differentiate one product offering from other products in the same product category. In addition, branding strategies are used sometimes in different product categories where competitors offerings in the same product category.

Bhat \& Reddy (1998) emphasized the importance of brand globalness and product category, whether functional or prestige, as determinants of new brand and or in the development of brand extension. For the development of a brand, it should be noted that local brands can meet customer satisfaction in functional and practical form, while prestige products meet the consumer's need for self-expression.

A study by Bharadwaj et al. (2010) on Indian consumers shows that Indian consumers have a higher preference for global brands than local brands from India and judge local brands lower in terms of brand image. Their research shows that when new products have substantial attribute changes, then functional local brands are preferred with brand new names. This becomes the basis of this study, i.e. to examine whether the indicators of brand formation for fashion products of SMEs in the creative industry form the product brand.

This study uses visual identity concept which has been published by Rufaidah, Razzaque \& Walpole (2003: 2423), which states that the design of products/services (e.g. corporate name, logo type, typography and color), corporate communication tools (e.g. slogan and visual communication) and physical environment of the organization (e.g. spatial design) are parts of visual identity that can enhance the corporate identity of the firm.

Referring to similar published literature of Melewar \& Saunders (1998), van den Bosch, Elving \& de Jong (2006) say that corporate visual identity consists of the following components: "corporate name, logo, color palette, font type, and a corporate slogan, tagline and/or descriptor and these may be applied on, for instance, stationery, printed matter (such as brochures and leaflets), advertisements, websites, vehicles, buildings, interiors, and corporate clothing. Sometimes architecture can be an important element in an organization's visual identity."

For the purposes of this study, the concept of branding strategy used in this study is adopted from the concept of company's visual identity combined with other concepts of branding strategy developed by several experts. This study defines branding strategy as a number of ways to form brand distinctiveness through product/service design (such as organization name, logo type, grammar, color, and other visual elements), a number of communication tools (such as print media, electronic media and social media) and physical environment (such as the environmental design in which the business is conducted).

Based on the aforementioned definition, there are three components that shape the dimension of a brand, namely, the design of products/services, marketing communication tools, the physical environment of the organization. To support the 
study of literature in this research, the concept from Kotler \& Keller (2012) has been used. However, modifications are made to the definition of each branding component. "Products are everything that can be offered to the market to satisfy wants or needs" (Kotler \& Keller 2012: G7). In this research, the component of branding strategy examined from product aspect is the product/service design offered by the SMEs in the creative industry for fashion products made from textiles. So product/service design in this research is defined as a number of product design elements that are unique or different from other competing products such as brand names, logos, letters, colors, styles, and other elements (Rufaidah et al., 2003: 2423).

Marketing communication (Kotler \& Keller 2012: G5) are the means by which firms attempt to inform, persuade, and remind consumers - directly or indirectly - about the products and brands they sell. Marketing communication tools are the tools by which companies use to inform, persuade, and remind consumers - directly or indirectly - about the products and brands they offer (such as print, electronic, and social media). The types of media being studied are print media (newspapers and magazines); broadcast media (radio, television); network media (telephone, cable, satellite, wireless); electronic media (audio recording, video recording, videodisc, CD-ROM, internet pages); and display media (billboards, signs, posters). Most non-personal messages go through paid media.

Rufaidah et al. (2003: 2423) proposed that the physical environment of organization is one of corporate visual identity factors which influences consumer perceptions. Considering that this research uses visual identity element as one of the pressing strategy components, the physical environment of organization becomes one of the branding strategy components. An example of a company's physical form is spatial design which is the design of space between interior and exterior environments in both public and private areas (companies/organizations). Spatial design elements include spatial layout, room condition, environmental condition and other elements. Therefore, physical environment of organization used in this research is defined as a number of elements of spatial design in the form of physical environment, spatial layout, room condition, environmental condition and other physical elements of a company.

As compared to previous research, this study is unique in that it is the first study explaining branding strategy based on consumer perceptions of fashion products produced by SMEs in West Java and the first study of branding strategy dimensions and their significant within SME industry. Consumer perceptions of the branding strategy applied by the SMEs in fashion creative industry in West Java has not been examined in any great detail. The second contribution of the paper lies in a replication of conceptualization and measurement of branding strategy which here is conceived of as the ensemble of three dimensions, namely, product design, marketing communication tools and physical environment. The object of the study is unique in its capability to provide support for the findings.

\section{RESEARCH METHODOLOGY}

The research applied a single cross-sectional method. In single crosssectional design, one sample of respondents is drawn from the target population and 
information is obtained from this sample only once (Malhotra 2010: 108). The method of analysis is descriptive. The study starts from primary and secondary data collection to identify and determine the branding strategy used by SMEs, especially those selling fashion products.

The population in this study is the consumers of fashion creative industry products produced by SMEs in West Java. Based on the calculations using Slovin's formula, the number of respondents required for this study is about ninety-seven respondents. However, the study has collected 129 respondents. The stages in this research activity started from primary and secondary data collection to identify fashion products in the creative industry produced by SMEs in West Java and product user responses to branding strategy used by SMEs of fashion products.

Prior to conducting survey activities to the target respondents, the existing conditions in the field has been directly observed, i.e. the business and consumers of fashion products in the creative industry. The cities and regencies that are qualified for the survey are those that have been considered to have fashion creative industry. The cities include Bandung City, Cimahi City and Cirebon City, while the regencies include Bandung Regency, West Bandung Regency, Garut Regency and Subang Regency. Representations of 3 out of 9 cities and 4 out of 18 regencies are considered to be quite representative. But in implementation, not all respondents were willing to fill it out the questionnaires, so the most responses are obtained from Bandung City, Cirebon City, Garut Regency and Subang Regency.

The main observation units in this research are SMEs in the creative industry, relevant organizations in West Java provincial government (such as Department of Industry and Trade, especially Promotion and Cooperation Sector). The population of the study is all consumers of creative industry products in West Java. This research focused on consumers of creative industry products that have lived in West Java for at least two years. In addition, the study also interviewed SMEs who produce fashion products that are part of the creative industry cluster. Sampling method used in this research is Simple Random Sampling.

This study focused on measuring the perceptions of consumers of creative industry products in West Java, especially fashion products produced by SMEs. The 1-to-5 Likert scale was used to show the degree of agreement (1 for strongly disagree to 5 for strongly agree). The operationalization of variables uses three dimensions to measure branding strategy, namely:

Product design. Product design is one of the strongest dimensions of branding strategy applied by most SMEs in West Java. The indicators of product design in this research are as follows: product brand uniqueness, uniqueness of product that makes it easy to remember, product design reflects product quality, product features compared to products from other regions, brand name reflects product exclusiveness, brand name uniqueness, product quality reflects brand name, billboard graphic design, the attractiveness of brochure graphic design, up-to-date product design to product exclusiveness, affordability, the attractiveness of logo, the familiarity of logo, unique logo reflects the quality of fashion products, the uniqueness of letters on the label, the uniqueness of the label, the uniqueness of 
different letters, more interesting color variations, the diversity of colors as product's characteristic and the diversity of colors as the added value of the product.

Marketing communication tools. Marketing communication tools are applied by SMEs that produce fashion products in the creative industry in West Java. The marketing communication tools are attractive branding strategy adopted by most SMEs in West Java. The indicators of marketing communication tools are as follows: newspapers as media of promotion, magazines and tabloids as media of promotion, blogs and websites as media of promotion, internet media as media of promotion, facebook as medium of promotion, twitter as medium of promotion, radio as medium of promotion and TV as medium of promotion.

Physical environment of the place of sale of fashion products. The place for selling fashion products (outlet) is part of the physical environment dimension. It is also applied by the SMEs that produce fashion products in the creative industry in West Java. The indicators are as follows: the strategic location of the outlet, the quality of facilities reflects the quality of service, the ease of access to public transportation to reach the outlet, ease of consumer service based on the spatial design of the outlet, cleanliness of the outlet, environmental care around the outlet, maintenance of public facilities, availability of parking area.

Aaker et al. (2011: 259) state that Likert scale is a scale indicating a statement of agreement or disagreement with the diversity of statements relating to attitudes or objects. Therefore, 20 items were used to measure product design, 8 items to measure marketing communication tools and 9 items to measure the physical environment of organization. Some items were negative items (i.e. number 8 and number 12). Negative items were used to avoid mistakes made by respondents when filling out the questionnaires. The instrument consists of two components, which are the respondent profile (location of residence, age, education, and income) and items to measure the branding strategy dimensions.

\section{RESULTS}

The results of the study discussed in this section explain the consumers' ratings of fashion products in the creative industry based on the indicators described in the previous section. The next section shows the percentage of consumer perceptions of fashion products based on the indicators studied. The majority of the evaluation results show an encouraging rate, but there are some indicators of which results are lower than fifty percent. These indicators are discussed in the conclusion section.

\section{Descriptive Statistics}

The profile of the respondents of the study are as follows: From the total of 129 respondents who were all West Javanese people spread in 27 regencies and cities, $55 \%$ were male and $45 \%$ were female; $32 \%$ were between $20-25$ years old, $6 \%$ were between $26-30$ years old, $12 \%$ were between $31-35$ years old, $16 \%$ were between 36-40 years, 19\% were between $41-45$ years old and $15 \%$ were over 45 years old; $39 \%$ were unmarried, $60 \%$ were married and $1 \%$ was widowed; $52 \%$ had master degree, $32 \%$ had bachelor degree, $11 \%$ had high school degree, $1 \%$ had diploma degree, $4 \%$ had-doctoral degree and none had elementary or junior high 
education; $40 \%$ were students, $22 \%$ were private employees, $4 \%$ were entrepreneurs, $17 \%$ were civil servants/military and $17 \%$ had other jobs.

Product design. Product design is one of the strongest dimensions of branding strategy applied by most SMEs in West Java. The results for indicators of product design are as follows: product brand uniqueness $(72.9 \%)$, product uniqueness $(65.9 \%)$, product design reflects product quality $(61.2 \%)$, product features compared to products from other regions (55.0\%), brand name reflects product exclusiveness $(55.0 \%)$, brand name uniqueness $(48.1 \%)$, product quality reflects brand name $(50.4 \%)$, billboard design graphic design $(56.6 \%)$, the attractiveness of brochure graphic design (71.3\%), up-to-date product design to product exclusiveness $(82.9 \%)$, affordability $(89.9 \%)$, the attractiveness of logo $(62.8 \%)$, the familiarity of logo $(48.8 \%)$, unique logo reflects the quality of fashion products $(47.3 \%)$, the uniqueness of letters on the label $(51.2 \%)$, the uniqueness of the label (39.5\%), the uniqueness of different letters (44.2\%), more interesting color variations $(55.8 \%)$, the diversity of colors as product's characteristic $(55.0 \%)$ and the diversity of colors as the added value of the product $(62,8,9 \%)$.

Marketing communication tools. Marketing communication tools are applied by SMEs that produce fashion products in the creative industry in West Java. The results for indicators of marketing communication tools are as follows: newspapers as media of promotion $(58,1 \%)$, magazines and tabloids as media of promotion $(68,2 \%)$, blogs and websites as media of promotion $(79,8 \%)$, internet media as media of promotion $(74,4 \%)$, facebook as medium of promotion $(82,9 \%)$, twitter as medium of promotion $(74,4 \%)$, radio as medium of promotion $(54,3 \%)$ and tv as medium of promotion (33.3\%).

Physical environment of the place of sale of fashion products. The place for selling of fashion products (outlet) is part of the physical environment dimension. The results for indicators of physical environment are as follows: the strategic location of the outlet $(88.4 \%)$, the quality of facilities reflects the quality of service $(79.1 \%)$, the ease of access to public transportation to reach the outlet (88.4\%), the ease of consumer service based on spatial design of the outlet $(73,4 \%)$, cleanliness of the outlet $(69,0 \%)$, environmental care around the outlet $(58,9 \%)$, maintenance of public facilities (48.1\%), availability of parking area (51.2\%).

\section{DISCUSSION}

Based on the results of the study on product design, it can be concluded that fashion product design in West Java is one of the indicators that shapes the uniqueness of creative economy in West Java. The indicators forming the design of fashion products as a characteristic of West Java are as follows: fashion products in West Java have distinctive brands compared with fashion products from other provinces; fashion products in West Java have unique characteristics that are easy to remember compared with fashion products from other provinces; the design of fashion products in West Java reflects a better quality than the design of fashion products from other provinces. The brand names used in fashion products in West Java reflect the uniqueness and quality of fashion products and more unique than those of other products. 
The graphic design of fashion products advertisement through billboards and brochures in West Java is interesting. The uniqueness of design of fashion products in West Java is always up to date. Fashion products in West Java are easy to find by consumers. However, the findings found that the use of the logo on fashion products in West Java did not attract the attention of consumers. The logos of fashion products in West Java are easy to recognize compared with those of fashion products from other regions. The uniqueness of logos of fashion products in West Java reflects the quality of fashion products. Unique fonts used on labels of fashion products in West Java add more attractiveness to the products. The letters used on labels of fashion products in West Java show the uniqueness of West Java. The letters used are unique and different from those used for fashion products from other regions. Fashion products in West Java offers more interesting color variations. The color diversity of fashion products in West Java reflects the added value of the products.

Based on the results of the study on marketing communication tools, it can be concluded that marketing communication tools used by SMEs to promote the fashion products in West Java are one of the indicators that shapes the uniqueness of creative economy in West Java. The indicators forming the marketing communication tools are as follows: the SMEs of fashion products in West Java use media such as newspapers, magazines and tabloids, blogs and websites to promote their products. Social media such as facebook and twitter are also used for promotion of fashion products in West Java because they are very popular among consumers. Social media like twitter also is one of the media that is also used to market fashion products in West Java region. In addition, fashion products in West Java are also promoted through broadcast media such as radio and TV.

Based on the results of the study on physical environment, it can be concluded that physical environment as place for selling the fashion products by SMEs in West Java is one of the indicators that shapes the uniqueness of creative economy in West Java. The indicators forming the physical environment as place for selling the fashion products are as follows: the location of the outlets of fashion products in West Java are strategic and easy to reach by consumers; the good facilities of the outlet reflects the quality of service. Public transportation is available anytime as the access to reach the outlet; the spatial design of the outlet facilitates consumers during service; the atmosphere of the outlet is convenient for consumers who are shopping; the cleanliness of the outlet is well preserved; the environment around the outlet is well preserved; and public facilities in the neighborhood of the outlet are well maintained.

\section{CONCLUSION}

The results of the study show that consumer perceptions of some indicators are below 50\%, mostly in visual branding indicators, such as the brand name uniqueness $(48,1 \%)$, the familiarity of logo $(48,8 \%)$, unique logo reflects the quality of fashion products $(47,3 \%)$, the uniqueness of the label $(39,5 \%)$ and the uniqueness of different letters $(44,2 \%)$. These results show that the role of brand names, logos, and typography designs has a very important part in the minds of consumers of creative products, especially in the fashion industry. The SMEs need to collaborate 
with graphic designers to leverage the role of visual graphic design so as to create unique brand names, logos and letters of fashion products in the minds of consumers and distinct brands compared to with those of similar competitors in the industry.

In relation to marketing communication tools, $33.3 \%$ of respondents stated that fashion products in West Java has been widely known from TV advertisement. So there is a potential to improve the performance of TV advertisement in marketing fashion products. Although advertising on TV is one of the most expensive forms of promotion, it is worth noting that SMEs in this industry use mutually beneficial partnerships with various industries and TV media managers to promote fashion creative industry products. Furthermore, only $48.1 \%$ of respondents stated that public facilities in the neighborhood of the outlet are well maintained. This needs to be a serious concern of SMEs with a response that the cleanliness of the sales place of fashion products in West Java show the cleanliness is well maintained. In other words, hygiene programs to keep the product's sales spot needs to be a priority and enhanced. So, cleanliness of the sales place or the outlet could become the identity physical environment.

\section{References}

Aaker, D., Kumar, V., \& Leone, R. (2011). Marketing Research, $10^{\text {th }}$ Ed. Wiley.

Aaker, D.A., \& Keller, K.L. (1990) Consumer evaluations of brand extensions. Journal of Marketing, 54 (1): 27-41.

Bhat, S., \& Reddy, S. K. (1998). Symbolic and functional positioning of brands. Journal of Consumer Marketing, 15(1), 32-43.

Bharadwaj, V., Kumar, A., \& Kim, Y.K. (2010) Brand analyses of US global and local brands in India: The case of Levi's. Journal of Global Marketing, 23 (1), 80-94

Instruksi Presiden Republik Indonesia Nomor 6 Tahun 2009 [Instruction of the President of the Republic of Indonesia Number 6 Year 2009]

Keller, K. L. (2008). Strategic Brand Management, Third Edition. Pearson Education Limited.

Kotler, P., \& Keller, K. (2012). Marketing Management, Fourteenth Edition. Pearson Education Limited.

Laporan Penelitian, Tim Inisiasi (taskforce) Ekonomi Kreatif Propinsi Jawa Barat 2011, Bappeda Pemerintah Provinsi Jawa Barat [Research Report, Team Initiation (taskforce) Creative Economy West Java Province 2011, Bappeda West Java Provincial Government]

Malhotra, N. K. (2010). Marketing Research : An Applied Orientation, Sixth Edition. Pearson. 
Rufaidah, P. (2012). Ekonomi Kreatif: Peluang \& Kebijakan. Tabloid Inspirasi, 25 Juni 2012 [Rufaidah, Popy. 2012. Creative Economy: Opportunities \& Policies. Inspiration Tabloid, June 25, 2012]

Strebinger, A. (2014). Rethinking brand architecture: a study on industry, company- and product-level drivers of branding strategy, European Journal of Marketing, Vol. 48, Issue 9/10, pp. 1804-1782

Singh, B. (2014). Measuring effectiveness of branding strategy using second order factor analysis. International Journal of Trade \& Global Business Perspectives, 3(2), 929-936 